\title{
Activity and food-restriction effects on gastric glandular lesions in the rat: The activity-stress ulcer
}

\author{
WILLIAM P. PARÉ and VINCENT P. HOUSER* \\ Pavlovian Research Laboratory \\ VA Hospital. Perry. Point, Md. 21902
}

Eighteen rats, 60 days old, and 18 rats, 110 days old, were housed in standard activity cages and fed $1 \mathrm{~h}$ each day for 21 days. Ten rats, 60 days old, and five rats, 110 days old, died before the end of the experiment. All rats that died revealed extensive lesions in glandular portions of the stomach. Control rats, housed in standard cages and also fed $1 \mathrm{~h}$ each day, did not die. Experimental rats that died were more active than experimental rats that survived, and ate less than survivors and normal control rats. This technique is proposed as a new animal model for studying gastrointestinal pathology.

Routtenberg \& Kuznesof (1967) reported an interesting study in which rats living in activity wheels and fed only $1 \mathrm{~h}$ each day increased their daily activity and progressively lost weight until starvation occurred. Control rats placed on the same feeding schedule but housed in standard laboratory cages without access to an activity wheel usually ate more than experimental rats and survived the duration of the experimental period. This "self-starvation" effect (Routtenberg \& Kuznesof, 1967) has been frequently replicated by Routtenberg (1968) and other investigators (Barboriak \& Knoblock, 1972; Spatz \& Jones, 1971; Strutt \& Stewart, 1970).

The present study was concerned with observing gastrointestinal pathology in rats of different ages which demonstrated the self-starvation effect. This interest was generated by the fact that consummatory variables have considerable effect on the development of stress ulcers (Paré, 1972: Paré \& Temple, 1973) and that younger rats, as compared to mature and old rats, are more susceptibie to food-deprivation effects, both in terms of body weight loss (Jakubcjak, 1969) and gastrointestinal pathology (Pfeiffer, Debro, \& Muller, 1966). This paper represents a preliminary report on the effects of $1-h$ feeding and access to a running wheel on ulcer developments in two groups of rats of different ages.

\section{METHOD}

Ss were 60 Sprague-Dawley rats. Thirty rats were approximately 60 days old $(250-279 \mathrm{~g})$. The other 30 rats were 110 days old $(352-400 \mathrm{~g})$. Eighteen rats from each age group were housed in standard Wahmann activity wheels. Each activity wheel included a $25 \times 15 \times 13 \mathrm{~cm}$ adjoining cage. A sliding door could separate the cage frorn its adjoining wheel. The other 12 rats in each age group served as controls and were individually housed in standard laboratory cages measuring $25 \times 17.5 \times$ $17.5 \mathrm{~cm}$. All rats were fed for $1 \mathrm{~h}$ in their respective cages, between 9 and 10 a.m., with granular Purina Rat Chow. Water

\footnotetext{
*The authors wish to thank L. Temple and $\mathrm{K}$. Isom for their technical assistance. Gratitude is extended to Luther Gilliam of the Medical Illustration Service. VA Hospital. Perry Point, Md.. for the photographic work.
}

was available to all rats ad lib. Rats housed in the activity cages had continuous access to the activity wheel except during the 1-h feeding period. Both activity and control rats were situated in the same room. Room temperature was maintained at $74^{\circ}-76^{\circ} \mathrm{F}$. Room lights were on between 6 a.m. and 6 p.m. Body weight and food consumption were recorded daily for all rats, as were the number of wheel revolutions for activity rats. If a rat died, the stomach was removed and inspected for ulcers. The number of ulcers and cumulative length (millimeters) of the ulcers were recorded. The study was terminated after 21 days; all remaining rats were then killed and the stomachs were inspected for ulcers.

\section{RESULTS}

Ten of the 60-day-old experimental rats died, whereas only five of the 110-day-old experimental rats died during the course of the experiment. Although more young rats died, this difference failed to reach statistical significance (Fisher's exact probability test: $p<.087$ ). None of the control rats in either age group died during the study. All activity rats that died manifested extensive lesions in the glandular acid-bearing portion of the stomach. Rumenal ulcers were not frequently observed (re Fig. 1). Stomachs from surviving rats were ulcer-free. These data are summarized in Table 1.

Daily food consumption for 60-day-old rats is illustrated by Fig. 2. For illustrative purposes, activity experimental rats are separated into a group of rats that survived ("survivors") and a group of rats that died ("casualties") during the experimental period. Since fatalities were recorded after the ninth day, only the first 9 days were used for statistical purposes. An analysis of variance design for repeated measures was used (Winer, 1962). The main effect of groups was significant $(F=4.15, d f=2 / 27, p<.05)$. This difference was attributed to the casualty group, which ate significantly less food as compared to control rats (Tukey a test, $p<.05$ ). Surviving rats were not significantly different from control rats in terms of food consumption.

Figure 3 illustrates mean daily activity values for 60-day-old survivor and casualty rats. Casualty rats were significantly more active than survivor rats $(F=8.65$, df $=1 / 16, p<.01)$, but their daily activity decreased sharply during the last few days of the study.

A number of interesting facts were demonstrated by this study. First, all casualty rats revealed extensive glandular ulcers. To what extent the gastrointestinal pathology contributed to the death of casualty rats can be answered only after extensive physiological study of this phenomenon. Second. practically all ulcers were located in the body of the stomach. This would mitigate the argument that these lesions were due solely to food deprivation. since starvation ulcers are almost exclusively' located in the rumen of the stomach (Paré \& Temple. 


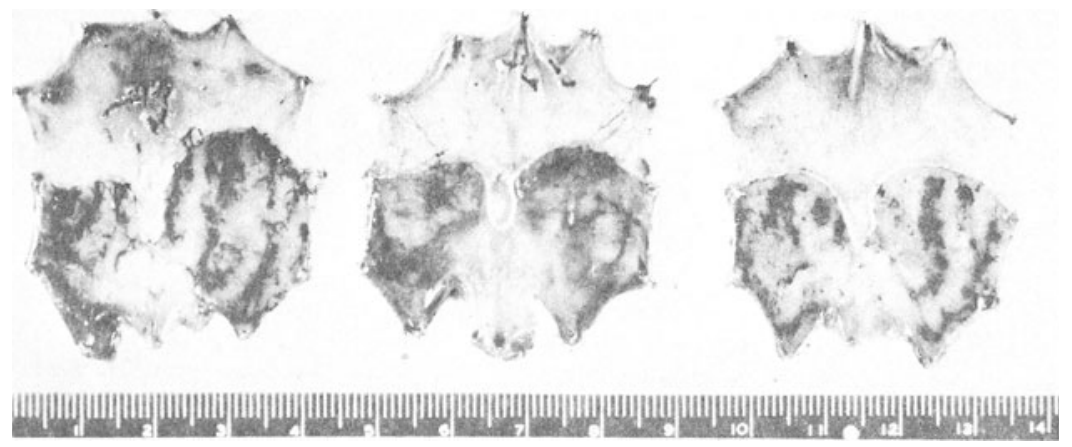

Fig. 1. Stomachs from three 60-day-oid rats that died after 9 days of living in activity wheels and restricted to 1 -h daily feeding. The severe linear lesions in the body of the stomach are covered with hemorrhagic slough.

Table 1

Summary of Stomach Ulcer Pathology for 60-Day-Old and 110-Day-Old Rats

\begin{tabular}{|c|c|c|c|c|c|}
\hline $\begin{array}{c}\text { Age } \\
\text { Groups } \\
\end{array}$ & & $\mathrm{N}$ & $\begin{array}{c}\text { Rats } \\
\text { With } \\
\text { Ulcers }\end{array}$ & $\begin{array}{c}\text { Mean } \\
\text { Ulcers } \\
\text { Per } \\
\text { Rat }\end{array}$ & $\begin{array}{c}\text { Mean } \\
\text { Length } \\
(\mathrm{mm})\end{array}$ \\
\hline 60 Days & $\begin{array}{l}\text { Experimental } \\
\text { Control }\end{array}$ & $\begin{array}{l}18 \\
12\end{array}$ & $\begin{array}{r}10 \\
0\end{array}$ & $\begin{array}{c}10.2 \\
-\end{array}$ & $\begin{array}{c}12.3 \\
-\end{array}$ \\
\hline 110 Days & $\begin{array}{l}\text { Experimental } \\
\text { Control }\end{array}$ & $\begin{array}{l}18 \\
12\end{array}$ & $\begin{array}{l}5 \\
0\end{array}$ & $\begin{array}{l}9.6 \\
- \\
\end{array}$ & $\begin{array}{c}16.4 \\
- \\
\end{array}$ \\
\hline
\end{tabular}

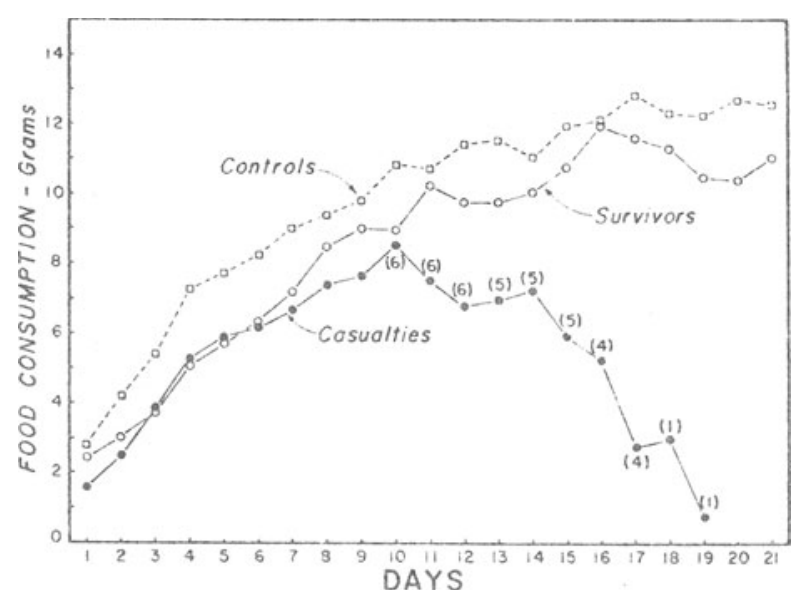

Fig. 2. Mean daily food consumption for 60-day-old control rats $(\mathbf{N}=12)$ and experimental activity rats. Experimental activity rats are separated in a survivor group $(N=8)$ and a casualty group $(\mathrm{N}=10)$. Numbers in parentheses for the casualty group represent the number of rats represented by that particular data point.

1973). It is also of some significance that these ulcers developed in the absence of any observable noxious stimulation (e.g., electric shock). However, the glandular ulcers observed in this study do resemble the "stress ulcer" reported by other investigators (Brodie, 1971). For this reason we have given the gastric ulcers developed by this animal model the preliminary designation of the "activity-stress ulcer."

\section{REFERENCES}

Barboriak, J. J., \& Knoblock, H. W., Jr. Gastric lesions in food-restricted young rats. Proceedings of the Society of

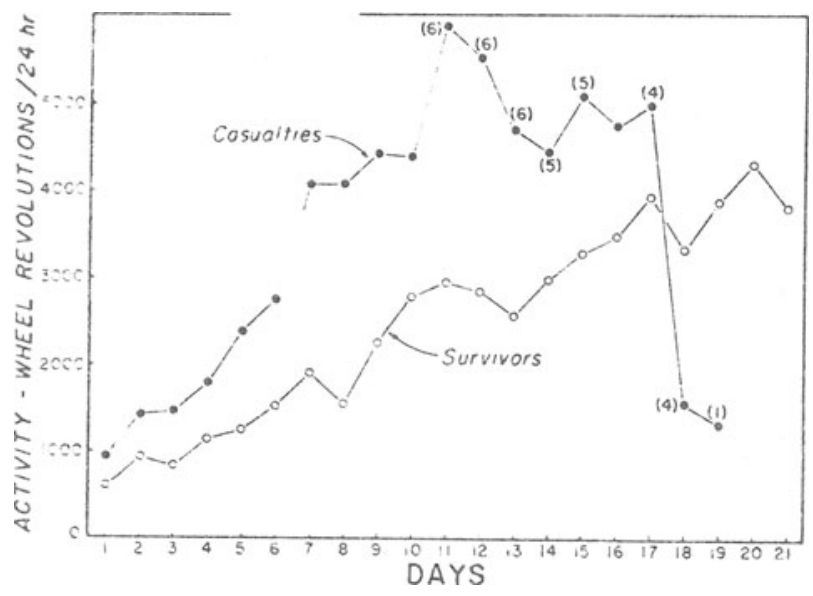

Fig. 3. Mean daily activity (wheel revolutions) for 60-day-old survivor $(N=8)$ and casualty $(N=10)$ rats from the experimental activity condition. Numbers in parentheses for the casualty group represent the number of rats represented by that particular data point.

Experimental Bioloby \& Medicine, 1972, 141, 830-832.

Brodie, D. A. Stress ulcer as an experimental model of peptic ulcer disease In C. J. Pfeiffer (Ed.), Peptic ulcer. Philadelphia: Lippincott, 1971. Pp. 71-83.

Jakubcjak, L. F. Effects of age and activity restriction on body weight loss of rats. American Journal of Physiology, 1962. 216, 1081-1083.

Paré, W. P. Conflict duration, feeding schedule, and strain differences in conflict-induced gastric ulcers. Physiology \& Behavior, 1972, 8, 165-171.

Paré, W. P., \& Temple, L. J. Food deprivation, shock stress and stomach lesions in the rat. Physiology \& Behavior, 1973, in press.

Pfeiffer, C. J., Debro, J. R., \& Muller, P. J. Gastric pathologic and biochemical changes induced by starvation of weanling rats. Life Science, 1966, 5, 509-519.

Routtenberg, A. "Self-starvation" of rats living in activity wheels: Adaptation effects. Journal of Comparative \& Physiological Psychology, 1968, 66, 234-238.

Routtenberg A \& Kuznesof, A. W. Self-starvation of rats living in activity wheels on a restricted feeding schedule. Journal of Comparative \& Physiological Psychology, 1967, 64, 414-421.

Spatz, C., \& Jones, S. D. Starvation anorexia as an explanation of "self-starvation" of rats living in activity wheels. Journal of Comparative \& Physiological Psychology, 1971, 77, 313-317.

Strutt, G. F., \& Stewart, C. N. The role of blood glucose in activity related self-starvation. Psychonomic Science, 1970, 18, 287-289.

Winer, B. J. Statistical principles in experimental design. New York: McGraw-Hill, 1962.

(Received for publication June 29, 1973.) 